\title{
Arbor
}

\section{Musulmanes y cristianos: La imposibilidad de una convivencia}

\section{Antonio Luis Cortés Peña}

Arbor CLXXVIII, 701 (Mayo 2004), 31-52 pp.

Uno de los hitos fundamentales de la Historia de España fue, sin duda, la guerra sostenida por los Reyes Católicos para la incorporación del reino de Granada al conjunto de territorios que formaban su Monarquía. Calificar de hito fundamental para nuestra historia tal acontecimiento no supone exageración historiográfica alguna dada la importancia derivada del mismo. Su trascendencia estuvo determinada no sólo por el hecho en sí, sino, además, por las múltiples consecuencias de todo orden, interno y externo, que se derivaron para la evolución posterior de la política hispánica.

Fuera de toda anacrónica alharaca nacionalista hay que convenir que la conquista de Granada fue ineludible preámbulo para llevar a cabo una política exterior que situó a la reciente Monarquía en uno de los puestos destacados dentro del panorama internacional del Occidente europeo. Por otro lado, a corto plazo, significó también la posibilidad de iniciar la formación de una nueva sociedad caracterizada por una serie de rasgos diferentes de los que habían estado presentes hasta entonces. Entre éstos, y de modo sobresaliente, hay que señalar el componente religioso, la exclusividad del mismo, como uno de los que iban a adquirir una nueva valoración, ya anunciada con anterioridad pero que a partir de ahora va a adquirir una fuerza incuestionable.

No me refiero sin más a que la nueva etapa inaugurada supone el fin del mito de la armoniosa convivencia de las tres culturas que, de una forma bien simplista, pregona por doquier tanto indocumentado, por desgracia con gran eco en los medios de comunicación. La expansión de di- 
cho mito ha tenido la fortuna de que, durante mucho tiempo, 1492 ha supuesto para una cierta historiografía tradicional una fecha de brusca separación entre una época de tolerancia y otra de intolerancia; sin embargo, no todo fue tan simple. En primer lugar, siempre hay que recordar, e insistir, que esa proclamada armonía no existió prácticamente nunca; sólo en periodos muy concretos se conoció una cierta tolerancia, siempre con la indiscutible y prepotente primacía de la religión profesada por el poder político imperante. Quiero ello decir que, en etapas concretas, la tolerancia existió, pero, como ha expresado Cardaillac,

Sur un principe inegalitaire, une cultura et deux sous-cultures, et sur un principe religieux, Précisons encore. Nous sommes en présence D’une societé basée sur une vision exclusive et théologique de la vérité, sur une vérité révélée par Dieu mais gérée par les theologiens dont le rappert à la vérité est précisément dognatique. Toute communauté exterieur est excluye du partage de la Vérité. Dans tout le Moyen Age les systèmes théologiques des trois religiones fonctionnent comme stratégies d'exclusion réciproque ${ }^{1}$.

Debemos, por tanto, una vez más, recordar que musulmanes y cristianos en la época medieval podían vivir bajo un mismo poder político, ahora bien, con diferentes leyes y sin mezclarse en muchos aspectos, por lo que habría que hablar más de coexistencia que de convivencia, coexistencia que iba a conocer en ambos bandos duras pruebas desde fines del siglo XI. En los países cristianos, los musulmanes solían vivir agrupados en calles o barrios, las morerías, algo que, como recuerda Ladero, ordenaban las leyes eclesiásticas europeas desde 1215 y las promulgadas por los reyes castellanos desde 1412, "pero nunca se cumplieron estrictamente hasta que, en 1480, Isabel lo ordenó ante las Cortes reunidas en Toledo y, en los meses siguientes, se llevó a cabo el apartamiento de mudéjares, y también de judíos, a barrios propios» ${ }^{2}$.

En las últimas décadas del siglo XV, asistimos, pues, sencillamente, al nacimiento de una época en la que la fuerte tendencia de los gobiernos a ejercer un poder centralizado y autoritario determinó que príncipes y dirigentes políticos buscasen en la homogeneidad ideológica de sus súbditos una de las bases principales para llevar a cabo un mejor intento de control de los mismos, algo que veían como necesario con el objeto de lograr una cohesión social indispensable, según su criterio, a la hora de llevar a buen puerto su acción de gobierno.

Si bien en la Corona de Castilla existían grupos de mudéjares que habían permanecido en sus tierras tras el avance hacia el sur de los ejércitos cristianos, su papel en la sociedad no tenía gran importancia dado su irrelevante número y, además, el paulatino deterioro que habían su- 
Musulmanes y cristianos: La imposibilidad...

frido no pocas prácticas y costumbres heredadas de sus ancestros; sin embargo, el importante contingente de población islámica, con pleno vigor de sus creencias y modos de vida, que la conquista de Granada convirtió en nuevos súbditos vino a cambiar la situación existente con anterioridad. Todo ello condujo a que, primero en Castilla, más tarde en todos los dominios de la Monarquía, se iniciase antes que en otros territorios europeos $^{3}$ un proceso de rechazo al «otro»-en este caso identificado con el musulmán ${ }^{4}-$, fenómeno que tan trágicas consecuencias tuvo para la historia de la Europa moderna.

Es dentro de estas coordenadas, expuestas sin duda de un modo esquemático, donde hay que situar el problema que vamos a tratar en las próximas páginas: ¿Fue posible el establecimiento de unas líneas de convivencia -0 , al menos, de coexistencia- entre musulmanes y cristianos en la Corona de Castilla en el reinado de los Reyes Católicos con una cierta garantía de persistencia en el tiempo? Veamos ante todo los antecedentes y el contexto histórico.

En los reinados anteriores a los Reyes Católicos habían sido numerosas las acciones bélicas que enfrentaron a las tropas castellanas con las granadinas; no obstante, los monarcas cristianos no se decidieron a emprender la conquista definitiva del reino nazarí, entre otras razones, por la inestabilidad interna de la propia Castilla. La situación se presentó bien diferente cuando Fernando e Isabel, solucionados los problemas sucesorios, impusieron la autoridad real entre sus súbditos. En ese momento una serie de factores lanzaron a los monarcas a la conquista definitiva de la Granada islámica, cuya mera existencia suponía una permanente fuente de inquietud en el sur de sus dominios. Los principales fueron éstos:

Aunque hoy día sean muchos los historiadores que no aceptan el concepto de Reconquista, prefiriendo hablar lisa y llanamente de conquista (término sin duda más de acuerdo con la realidad objetiva de aquel largo proceso), no hay que olvidar, sin embargo, que había sido un concepto cultivado a lo largo de los siglos medievales por los grupos dominantes de la sociedad cristiana, entre los que se fueron formando una serie de tópicos en torno al mito de la pérdida de España, que influyeron en «buena parte de las actitudes individuales y colectivas de los cristianos viejos ${ }^{5}$, por lo que a fines del siglo XV se hallaba extendido entre una mayoría de los mismos, lógicamente con distintos niveles de profundización. Nada extraño, pues los mismos musulmanes eran conscientes de este pensamiento cristiano, como lo expresa Ibn 'Idari, autor del Bayan, quien puso 
en boca de Fernando I ( $†$ 1065) las siguientes palabras dirigidas a los andalusíes:

Nosotros hemos dirigido hacia vosotros los sufrimientos que nos procuraron aquellos de los vuestros que vinieron antes contra nosotros y solamente pedimos nuestro país que nos arrebatasteis antiguamente al principio de vuestro poder, y lo habitasteis el tiempo que os fue decretado ; ahora os hemos vencido por vuestra maldad. ¡Emigrad, pues, a vuestra orilla [allende el estrecho] y dejadnos nuestro país!, porque no será bueno para vosotros habitar en nuestra compañía 6 .

En otra ocasión manifesté:

Por supuesto, la idea de reconquista no había surgido de un modo espontáneo entre los cristianos peninsulares, sino que su aparición y su paulatina expansión debían mucho a la labor realizada al respecto por algunos grupos sociales entre los que cabe destacar, en un primer momento, a los mozárabes emigrados hacia el Norte desde las tierras andalusíes. Con posterioridad, y de forma creciente, serían los estamentos privilegiados -nobleza y clero-, encabezados por los mismos monarcas, quienes se convertirían en sus más acérrimos defensores y propagadores ${ }^{7}$.

Parece claro asimismo que a la idea de reconquista se unió la de Cruzada, de rancia tradición en la Cristiandad occidental ${ }^{8}$ y que, tras la caída de Constantinopla y el avance turco, volvía a estar en la boca de los dirigentes cristianos, al margen por supuesto de que dicho concepto encerrase en verdad claros intereses políticos y económicos. En el caso que nos ocupa, la justificación última utilizada para la guerra era luchar contra un poder político no cristiano que impedía la expansión evangelizadora, por lo que «la conquista de Granada por los Reyes Católicos fue una cruzada contra los moros, enemigos de nuestra santa fe católica, además de ser una empresa de recuperación o reconquista territorial ${ }^{9}$. Además, a los monarcas les interesaba extender la idea de cruzada, ya que la misma llevaba anexa la posibilidad de auxilio, aunque fuese moral en la mayor parte de las ocasiones, de los restantes países de la Europa occidental, donde la lucha contra el Islam se consideraba, al menos en teoría, como una empresa común de la Cristiandad.

Por otra parte, Isabel y Fernando, preocupados por el afianzamiento de su política de reconstrucción de la monarquía, debieron ver en la guerra contra el musulmán la posibilidad de canalizar las energías de la turbulenta nobleza castellana hacia una empresa que, en virtud de previsibles ganancias materiales, podía frenar las discordias internas y satisfacer «a costa del enemigo» ambiciones de todo tipo.

Hay que indicar también que en Castilla, al igual que en otras zonas de Europa, se estaban extendiendo nuevas tendencias político-ideológicas que, en busca de la homogeneidad de los súbditos, propugnaban la 
unidad de creencias religiosas como uno de los instrumentos imprescindibles para construir un estado diferente, absoluto y centralizado, en el que no era posible, por tanto, la coexistencia con el Islam ${ }^{10}$, lo que no sólo iba a influir en la contienda bélica, como culminación de todo un proyecto político heredado, sino, de un modo más claro, en los acontecimientos inmediatamente posteriores.

La desaparición del reino nazarí fue festejada en toda la Península, así como en el resto de la Cristiandad occidental, que vivía atemorizada por la impetuosa expansión de los turcos; se cantaron tedeums, se compusieron poemas, y la atención se volcó hacia aquella nueva potencia que surgía en Occidente en defensa de la Cristiandad. Renacía en algunos sectores la utópica esperanza, nunca extinguida, de reconquistar los Santos Lugares. Sin duda con esa intención, o si se prefiere, mediante este pretexto, el papa Julio II concedió a Fernando V el título de rey de Jerusalén; pero el político don Fernando, como lo llamó Gracián, sabía distinguir muy bien la realidad de la fantasía, por lo que sus miras políticas tuvieron unos objetivos mucho más pragmáticos y cercanos.

\section{Las capitulaciones}

La conquista de Granada, con algunas excepciones de rendición incondicional de las que el caso de Málaga es el más notorio, se fue consolidando a través de sucesivos acuerdos -firmas de capitulaciones-con los poderes que dominaban en las distintas zonas del reino nazarí, acuerdos en los que desempeñó un importante papel la intervención de la reina Isabel ${ }^{11}$. Dichas capitulaciones de rendición, conforme avanzaban las campañas de conquista, se fueron haciendo cada vez más magnánimas, hasta el punto de que se puede dudar si los Reyes pensaban cumplirlas en su integridad o eran más bien una estratagema para conseguir la conquista definitiva del último reducto islámico ${ }^{12}$; al menos, la benevolencia de los términos de las capitulaciones pueden también interpretarse como una clara muestra de los fervientes deseos de los monarcas cristianos por terminar una guerra que había costado demasiadas vidas y dinero. Las que pusieron fin a la guerra, las que afectaron a la ciudad de Granada y a la Alpujarra ${ }^{13}$, no pueden ser más elocuentes al respecto.

El sultán vencido y los suyos se comprometían a guardar fidelidad a los Reyes Católicos y éstos, por su parte, se comprometían a garantizar la seguridad personal y material de Boabdil, su familia y colaboradores inmediatos, a los que se compensaba con pensiones generosas y la admi- 
nistración de buena parte de la Alpujarra. Quizás la lectura de algunos de los puntos de dichas capitulaciones resulte el mejor exponente para mostrar lo conseguido por el soberano nazarí para él y para sus súbditos. Helos aquí:

Item es asentado y concordado que sus altezas y sus descendientes, para siempre jamás dejarán vivir al dicho Rey Muley Baudili y a los dichos alcaides y alcaldis y sabios y muftíes -al-faquíes- y alguaciles y caballeros y escuderos y viejos y buenos hombres y comunidad chicos y grandes, estar en su ley y no les mandarán quitar sus algimas y çumaas y almuédanos y torres de los dichos almuédanos para que llamen a sus açalaes y dejarán y mandarán dejar a los dichos algimas sus propios y rentas como ahora los tienen y que sean juzgados por su ley sarracena con consejos de sus alcaldis según costumbre de los moros y les guardaran y mandaran guardar sus buenos usos y costumbres.

Item es asentado y acordado que no les tomarán ni mandarán tomar sus armas y caballos ni otra cosa alguna, ni en tiempo alguno para siempre jamás, excepto todos los tiros de pólvora grandes y pequeños que han de dar y entregar luego a sus altezas.

Item es asentado y acordado que ningún judío no sea recaudador ni receptor ni tenga mando ni jurisdicción sobre ellos.

Item es asentado y acordado que a ningun moro o mora non haga fuerza a que se torne cristiano ni cristiana ${ }^{14}$.

Además, se les permitía a los granadinos emigrar libremente al otro lado del mar durante el plazo de tres años, pudiendo enajenar previamente sus propiedades ${ }^{15}$. En caso de que optasen por permanecer en sus tierras, disfrutarían de franquicias fiscales durante dicho período, transcurrido el cual, volverían a tributar de acuerdo con el régimen impositivo nazarí. El derecho islámico sería seguido en todo pleito entre granadinos; en caso de fricción con cristianos, las partes litigantes deberían someterse a la decisión de jueces mixtos nombrados al efecto.

Todavía más. Con objeto de facilitar el desarrollo de la vida colectiva, los monarcas se apresuraron a nombrar una especie de "Ayuntamiento" o «Concejo» musulmán integrado por 21 regidores, de los que dos eran alfaquíes, tres escribanos, un intérprete y una larga serie de «alamines» que representan a los distintos oficios existentes en la ciudad.

A pesar de tan amplias concesiones, y pese a que formalmente las capitulaciones no tenían el carácter de mercedes o privilegios reales, sino que su naturaleza jurídica era de tipo contractual ${ }^{16}$, la mayoría de los grupos cultos y también los principales dirigentes nazaríes, conscientes de que la realidad pasaría bien pronto a ser distinta, emigraron, al sentirse incómodos en la nueva situación. Nada mejor para las pretensiones 
Musulmanes y cristianos: La imposibilidad...

de los vencedores, quienes facilitaron estas salidas, ya que así se favorecía la desarticulación de la sociedad musulmana, privándola de unas minorías rectoras, cabecillas naturales en caso de cualquier veleidad de revueltas ${ }^{17}$. Estos grupos debían ser conscientes de que los Reyes Católicos no tenían intención de perpetuar la dualidad social surgida en las capitulaciones, sino la de ganar tiempo mientras se adoptaban las medidas apropiadas que lograsen la integración de los nuevos súbditos. Algo totalmente coherente con el eje político que había guiado a Fernando a lo largo de la guerra, cuyos proyectos se hallaban claramente expresados en la carta que, en pleno periodo bélico, el soberano había dirigido a Tendilla, a la sazón embajador en Roma, el 14 de noviembre de 1486, en la que le instaba a presionar para el logro del anhelado patronato regio; en la misma expresaba que dicho eje «consistía en asegurar la unidad católica en todos sus dominios, heredados o adquiridos de nuevo» ${ }^{18}$.

El mismo Boabdil, con gran alivio de los Reyes y de las autoridades cristianas instaladas en Granada, que no dudaron de presionar al respecto, no permanecería mucho tiempo en su señorío alpujarreño, y así, en octubre de 1493, tras haber trocado sus posesiones por una fuerte indemnización en metálico, marchó a Marruecos seguido por más de seis mil seguidores. Era la forma más visible de ruptura con el pasado. Para los granadinos que permanecieron aquí se inició una dura y difícil etapa de coexistencia, cuyo final no pudo ser más trágico.

\section{Mudéjares y repobladores}

La conquista había significado para la mayor parte de los granadinos su paso a la condición de mudéjares, regulada por los términos contenidos en las capitulaciones, dejándoles conservar una cierta organización que permitiese de modo más fácil tanto su control como la cobranza de los tributos; la misma fue puesta en principio en manos de alguaciles mudéjares, quienes, vistos como símbolo del poder castellano «a causa del apoyo que prestaron a la Corona en su intento de una administración local autónoma ${ }^{19}$, se convirtieron en objeto de repulsa para sus correligionarios ${ }^{20}$. Ahora bien, puede decirse que, en general, las capitulaciones permitieron mantener una cierta sensación de tranquilidad hasta fin de siglo, pues su letra se cumplió en gran parte, aunque con la conciencia, entre los vencedores, de que la conquista no había terminado mientras no se consolidase la implantación castellana, algo que se pretendía lograr mediante dos procedimientos: uno, la incorporación de repobladores cris- 
tianos viejos, con la finalidad de romper la enorme desproporción entre la población musulmana y la cristiana, desproporción que era contemplada como un potencial peligro de cara al futuro; otro, la asimilación de la población vencida, algo perseguido por el poder real a raíz de la misma conquista del reino ${ }^{21}$, hecho muy difícil de conseguir dada la fortaleza que los mudéjares presentaban en cuanto al mantenimiento tanto de sus creencias religiosas, como de su estructura social y de sus costumbres ancestrales ${ }^{22}$. Por este motivo, no fue extraño que en algunos casos comenzara a alterarse el espíritu de las capitulaciones; así, las contribuciones o servicios extraordinarios de 1495 y 1499 o la hábil estratagema para recoger las armas de los mudéjares -la promesa de solucionar la carestía de los habitantes de la ciudad con la entrega de una importante cantidad de cereales a cambio del depósito previo de la citadas armas-. Incluso, en algunas comarcas concretas, no sólo se alteró el espíritu de los pactos, sino la misma letra, así, en 1495, los mudéjares de la comarca de los Vélez conocieron depredaciones en sus propiedades por parte de los cristianos de las vecinas tierras de Lorca; asimismo expresaron a los monarcas «varias quejas, entre ellas, que el corregidor de Vera, Diego López de Burgos, no les permitía la práctica de sus usos y costumbres» ${ }^{23}$.

Estas enfrentadas actitudes -marcadas en un bando por la prepotencia del vencedor y, en el otro, por el rechazo a una asimilación integradora- hicieron inevitable el empeoramiento de la situación de los musulmanes, agravada porque desde el poder comenzaron a ser tratados, dentro de la legalidad, con la peor medida posible: en la ciudad de Granada y su vega podían, por ejemplo, vender casas y tierras, pero no comprarlas, ya que lo que se pretendía era instalar cristianos, medida alentada desde la misma Corona, acentuando ahora la práctica de una política ya presente en la repoblación desde fines del siglo XI, en la que se buscaba la garantía de lealtad de los habitantes del territorio conquistado ${ }^{24}$. De hecho, 1498 fue un año clave en la consolidación de la nueva actitud legal por parte de las autoridades cristianas granadinas, cuyo cabildo no dudó en acordar una serie de normas bien significativas: separación de residencia entre cristianos y mudéjares, separación de alhóndigas...; Talavera, «en calidad de regidor, sancionó estos mandatos y como arzobispo impuso pena de excomunión a quien los quebrantase» ${ }^{25}$. Nada extraño, pues, que desde los mismos comienzos del nuevo sistema la posibilidad de convivencia entre ambos pueblos se manifestase llena de obstáculos. Como expresó el profesor Szmolka Clares,

el pueblo, tanto vencedores como vencidos, no podía aceptar una situación que iba contra sus intereses y convicciones. El mudéjar por ser refractario a una cultura y a 
Musulmanes y cristianos: La imposibilidad...

unos modos de vida diametralmente opuestos a los vernáculos. El repoblador por su incomprensión de la realidad granadina y el lógico deseo de mejorar su nivel de vida, pues para eso había emigrado a un país desconocido y difícil ${ }^{26}$.

Mientras que la población musulmana del antiguo reino, primero por la guerra y después por la emigración, vio disminuidos sus efectivos de modo considerable -aunque siguió siendo mayoritaria-, la entrada de repobladores cristianos fue intensa entre 1485 y 1499: se han calculado entre treinta y cinco mil a cuarenta mil, con sus familias la inmensa mayoría, que llegaron de Andalucía y, en menor proporción, de Castilla la Nueva y Murcia $^{27}$. De hecho la nueva estructura poblacional del reino se concibió, de modo general con dos zonas claramente diferenciadas:

Una marítima, vinculada al realengo, destinada a ser repoblada por cristianos, con abundantes repartimientos, alentada con generosas y excepcionales franquicias, y centrada en torno a la defensa y a las operaciones mercantiles; otra interior, preferentemente mudéjar y señorial, aunque salpicada por ciudades de realengo con población cristiana, inserta en actividades agropecuarias y artesanales, con peor trato fiscal y abocada a articularse con la costa y sus puertos ${ }^{28}$.

La Corona procedió, en consecuencia, a numerosos repartos de tierras y otros bienes raíces y, cuando no era posible, apoyó su compra por los repobladores. En general, se siguieron los métodos de repartimiento que habían llegado a su perfección durante el siglo XIII en el valle del Guadalquivir y Murcia. Se poblaron por completo todas las grandes plazas del interior: Ronda, Alhama, Loja y las villas de la Vega, Baza, Guadix. Con la excepción del litoral de la Alpujarra, donde, por miedo a los corsarios berberiscos, apenas había pequeñas aldeas y alguna fortificación, también se repoblaron las de la zona costera: Marbella, Málaga, VélezMálaga, Almuñécar, Salobreña, Almería y Vera fueron los puntos más destacados. En la capital hubo avecindamiento de cristianos viejos gracias a las facilidades existentes para comprar bienes de los musulmanes que optaron por la emigración; de modo que en 1498 los pobladores cristianos eran ya numerosos, y los musulmanes, tras un acuerdo forzado, se concentraron en el Albaicín, la Antequeruela y otros arrabales.

La Corona otorgó pocos señoríos jurisdiccionales o, mejor dicho, las concesiones a los grandes magnates fueron de menor importancia, siempre en áreas rurales interiores pobladas por mudéjares, con lo que el señor adquiría responsabilidades de gobierno y administración intermedias y el poder real permanecía por encima y conservaba, si llegaba el caso, capacidades arbitrales. No obstante, el régimen señorial siguió con vigencia, ya que «los Reyes Católicos concibieron para el reino de Granada una organización política nucleada en torno al poder señorial de las ciudades» ${ }^{29}$. 
La administración del reino de Granada se organizó según los modelos empleados en el resto de la Corona de Castilla, pero sin el lastre que suponía la herencia del pasado, lo que permitió acentuar el ejercicio de la autoridad regia. El mando militar del reino correspondió al conde de Tendilla, don Íñigo de Mendoza, con el cargo de Capitán General y residencia en la Alhambra de la que era alcaide, convirtiéndose en uno de los grandes organizadores del reino recién conquistado.

La administración municipal, organizada y encabezada por corregidores y pesquisidores, se basaba en regimientos reducidos, que, por la primera vez, fueron de directo nombramiento regio. En los primeros años, lo fundamental fue la presencia de organizadores, delegados de la Corona, y, por encima, el secretario real Hernando de Zafra, que se afincó en Granada en 1492 y, junto con el citado conde de Tendilla y el arzobispo fray Hernando de Talavera, formó la cúspide de la nueva organización castellana del reino.

Mientras la nueva estructura política se gestaba, no hicieron más que crecer la desconfianza y la antipatía entre vencedores y vencidos, aumentando cada día más los incidentes en la difícil convivencia de ambas comunidades. $\mathrm{Si}$, por un lado, podía constatarse una creciente y pertinaz resistencia de los mudéjares a integrarse en la nueva situación, por otro, resultaba evidente la escasa voluntad de asimilarlos por parte de los repobladores cristianos, una mayoría de los cuales, para reafirmar su postura, recurrían, de forma consciente o inconsciente, a la ideología de la reconquista, la cual consideraba que con la guerra se había recuperado «lo que antaño fuera de sus ancestros y que, por lo tanto, no entiende ni acepta la continuidad de la presencia musulmana» ${ }^{30}$, a lo que se añadía un concepto más primario, el de «tierra sometida», según el cual los habitantes derrotados estaban expuestos a cualquier tipo de humillaciones ${ }^{31}$; de hecho no eran pocos los repobladores que consideraban a los musulmanes como el enemigo tradicional al fin derrotado.

Junto a estas premisas, sustentadas en distintos grados por los repobladores e, incluso, por una mayoría de las autoridades locales, intervinieron además dos importantes factores que explican las actuaciones llevadas acabo: el miedo y la codicia. El recelo hacia ellos existió desde un principio, así, por citar sólo un ejemplo, tras la conquista de Baza no sólo quedó ocupada la alcazaba por un contingente armado castellano, algo lógico como medida preventiva ante la continuación de la guerra, sino que se procedió al desalojo de mudéjares de la Almedina, centro neurálgico y amurallado de la ciudad ${ }^{32}$. Mejor prueba aún de este miedo la tenemos, 


\section{Musulmanes y cristianos: La imposibilidad...}

finalizada la guerra, en el mismo Hernando de Zafra, quien en todo momento consideró al mudéjar no como nuevo súbdito de la Monarquía, sino como el enemigo vencido al que era necesario vigilar; de ahí que llegara a escribir «yo me huelgo mas de velles [a los mudéjares] allende que no estén aquende» y que, por supuesto, no fuera partidario de las vecindades mixtas, «ya que «es un buen consejo tener antes al enemigo lejos que cerca», lo que nos da idea del miedo y recelo que llevará a los cristianos a adoptar medios defensivos particulares [...]; pero también a plantearse una lucha ideológica cuyas manifestaciones serán el vilipendio y el descrédito del mudéjar» ${ }^{33}$. Dentro de este contexto, Zafra llegó incluso a criticar la política regia de reducir los efectivos militares conforme avanzaba la repoblación cristiana, porque siempre desconfiaba y tenía presente la posibilidad de colaboración de los granadinos con los musulmanes magrebíes ${ }^{34}$.

El otro factor aludido, la codicia, pronto se iba a manifestar entre los vencedores como uno de los claros impedimentos en contra del acercamiento entre las dos comunidades. El profesor Barrios ha escrito al respecto:

Los abusos se perpetran en todos aquellos lugares y campos de actividad en que es posible: en la emigración legal, la amparada por la Corona, los atropellos de los capitanes de las propias embarcaciones fletadas para ello fueron constantes, por más que los reyes los persiguieron en ocasiones con castigos ejemplares [...] Eran, con todo, más comunes los abusos provocados desde la misma justicia, cuya intervención a partir de un supuesto delito conducía a la arbitraria requisa de bienes del infractor, que difícilmente los recuperaría, y mucho menos en su totalidad, incluso en el caso de que la sentencia le fuera favorable $[\ldots]^{35}$.

En algunas ocasiones, la actitud violenta de las comunidades repobladoras hacia los mudéjares venía determinada por las líneas seguidas en los repartimientos de las tierras que se les concedían, como sucedió en Vélez-Málaga, donde se les otorgó a la mayoría de los cristianos repobladores unas parcelas no mucho mayores que las poseídas por los campesinos mudéjares de las alquerías cercanas, lo que llevó a virulentas reclamaciones de los primeros, quienes terminaron por lograr unas asignaciones mayores a costa de las propiedades de los musulmanes ${ }^{36}$. La codicia de los vecinos cristianos en todo el reino fue causa de fricciones y tensiones motivadas en no pocas ocasiones por estas exacciones de la propiedad, llegándose a límites tan insufribles que los Reyes Católicos no siempre claudicaron ante sus reivindicaciones e, incluso, se vieron obligados a intervenir con el fin de atajar los casos más flagrantes; por ejemplo, en diciembre de 1496 recordaron a los corregidores del obispado de Málaga que se frenaran las denuncias contra los mudéjares por poseer 
armas escondidas -la pena era la pérdida de éstas y de todos sus bienes, siendo la mitad de los mismos para el acusador-, ya que se hacían acusaciones por «un punnal viejo o hierro viejo que les fallaron por su casa» $\mathrm{y}$, todavía más, se habían recogido quejas de mudéjares a quienes se había multado por tener tijeras en sus moradas ${ }^{37}$. Esta descontrolada avidez incorporó, por tanto, un tono más duro al papel prepotente adoptado por un sector importante de los cristianos viejos ${ }^{38}$.

Todos estos factores iban asimismo a tener un formidable apoyo en la religión como argumento que resultaría contundente e inapelable, y, de este modo, los repobladores, faltos de otros justos razonamientos que sirviesen de base a sus exigencias, no dudaron en utilizar la cuestión religiosa para dar validez a su postura frente a los derechos de los mudéjares.

\section{La actitud de la Iglesia}

A pesar de lo acordado en las capitulaciones y de la mansedumbre evangelizadora del arzobispo Talavera, la Iglesia que se implanta en Granada fue una Iglesia vencedora y triunfante: la advocación de muchos templos a la Encarnación -uno de los dogmas cristianos más inasimilables por la mentalidad islámica- muestra bien la firmeza con la que se quería cimentar el nuevo edificio religioso, al que se veía como restauración de la cristiandad anterior a la invasión islámica.

Por otro lado, la concesión pontificia del Patronato Real -bulas de Inocencio VIII que culminaron con la Ortodoxae fidei de 13 de diciembre de 1486- no sólo convirtió a la Iglesia granadina en modelo de lo que iba a ocurrir después en las Indias, sino que imbricó de modo más profundo y directo a la propia Corona en el proceso de asimilación religiosa iniciado desde el primer momento de la conquista ${ }^{39}$, no en vano una vez más se hacía uso de la religión como instrumentum regni.

La atracción hacia el cristianismo de los vencidos comenzó sin violencia; el austero fray Hernando, sin perder de vista su radical rechazo del islam y su objetivo final de lograr el éxito en la conversión de los musulmanes granadinos, proyectó un proceso de cristianización en el que la caridad y la utilización de la psicología a nivel colectivo e individual estaban en la base de su catequesis, proceso que, en estos primeros años y «de acuerdo con la voluntad de la Corona, limitó su actividad misionera a la ciudad de Granada, pues su elevado porcentaje de población mudéjar era un constante peligro para la seguridad del reino» ${ }^{40}$. Szmolka ha escrito al respecto: 
Musulmanes y cristianos: La imposibilidad...

El arzobispo visitaba los enfermos, repartía limosnas y daba sustento a los huérfanos; estudió árabe y recomendó esto mismo a varios sacerdotes y religiosos. Siguiendo estas normas, fray Pedro de Alcalá compuso una gramática y diccionario árabes. Se bendijeron algunas mezquitas para establecer en ellas las primeras parroquias, pero persistieron la mayoría ${ }^{41}$.

En 1499, cuando volvieron los Reyes Católicos a la ciudad, convencidos ya para entonces de la necesidad de acelerar el proceso de una mayor castellanización del reino granadino, el recibimiento de una población cuyo aspecto externo denotaba que una gran mayoría seguía totalmente apegada a sus hábitos y costumbres, bien alejado de los castellanos, agradó poco a los soberanos que no dejaban de contemplar con recelo una masa de súbditos tan «exóticos»; cierto que ya se habían producido conversiones al cristianismo entre los mudéjares granadinos, pero en cantidades poco importantes, lo que, para quienes defendían la adopción al respecto de medidas más radicales, convirtió a Talavera en fácil blanco de críticas severas ante lo escasamente conseguido con sus métodos de cristianización, que indudablemente necesitaban un margen amplio de tiempo para verificar la efectividad de sus propósitos ${ }^{42}$.

El hecho fue que poco antes de la nueva marcha de los Reyes de la ciudad granadina, llegó a la antigua capital nazarí fray Francisco Jiménez de Cisneros, ya arzobispo de Toledo, que, tras un primer momento en el que se sumó a los métodos de Talavera, con quien compartía plenamente los objetivos finales, pronto se convirtió en el adalid del sector que preconiza unas medidas más duras para conseguir que los musulmanes granadinos aceptasen el bautismo. Su celo se iba a manifestar de modo especial con los «elches»-denominación dada a los renegados y sus descendientes-, tomándose sobre ellos, a pesar de estar protegidos por las capitulaciones, radicales medidas evangelizadoras, apoyadas en un principio por los monarcas.

Si las relaciones entre vencedores y vencidos habían atravesado hasta entonces tensiones y pruebas difíciles, la intransigente actuación de Cisneros, cuyo acto más simbólico fue la confiscación y quema pública de libros islámicos ${ }^{43}$, iba a resultar determinante de la inmediata insurrección armada de los mudéjares.

\section{Las revueltas de fin de siglo}

La nueva actitud en el tema religioso vino a unirse a la política de la Corona, persistentemente presionada por la creciente población cristiana 
que se había instalado en Granada, que desembocó incluso en el acuerdo alcanzado con los representantes mudéjares para que su comunidad viviese en barrios separados de los cristianos. Szmolka ha precisado:

A esta medida siguen las disposiciones prohibitivas de la mezcla de ambas comunidades. En consecuencia, y por orden de fray Hernando de Talavera, se prohíbe a los cristianos, bajo pena de excomunión, vender vino a los mudéjares, alquilarles casas para sus bodas, comprar en sus carnicerías, utilizar sus baños, servirse de parteras moras habiéndolas cristianas, etc. Asimismo se ordena que haya dos alhóndigas, una para cada comunidad [...] Con disposiciones como éstas, que no fueron las únicas, se fueron ensanchando las diferencias que separaban a cristianos y mudéjares y creando en éstos un sentimiento de malestar que desembocará en los sucesos de 1499 y $1500^{44}$.

Ante la asfixiante situación, el 18 de diciembre de 1499 los habitantes del Albaicín se sublevaron, pero la rápida actuación del conde de Tendilla, con la ayuda de fray Hernando, logró con rapidez el control de toda la ciudad, lo que fue seguido -ante la promesa del perdón en caso de aceptar el bautismo- por la «conversión» al cristianismo de un crecido número de musulmanes. Desde un principio esta conversión es vista por los musulmanes como un hecho forzado, antes incluso del decreto de 1502, como prueba la qasida compuesta por un morisco anónimo y enviada al sultán otomano Bayaceto II en una petición de ayuda (año 1501), en cuyos versos «el poeta acentúa el hecho de que siempre había sido la intención e los musulmanes el retener su fe» ${ }^{45}$.

Mientras tanto, la inquietud y los rumores más diversos se propagaron fuera de la capital granadina y, a principios de año, se levantan los mudéjares de la Alpujarra y sierras de Almería, los cuales mantendrán en jaque a los cristianos hasta fines del verano de 1500. Por su parte, el rey Fernando opta por suspender las capitulaciones al entender que éstas habían sido rotas por los mudéjares al sublevarse, y, salvo algunos casos puntuales como en Ronda o Güéjar en los que los rebeldes fueron expulsados o reducidos a la esclavitud, les ofrece la alternativa de aceptar el bautismo o pagar una fuerte indemnización de guerra si no se convierten, convencidos los reyes que dada la magnitud de la multa, la mayoría elegiría la conversión ${ }^{46}$. Acabará consiguiendo lo primero, no sin antes verse obligado a movilizar tropas en Andalucía y Murcia para llevar a cabo lo que algún cronista presenta como una nueva «conquista de Granada».

Para el otoño de 1500 la situación parecía controlada. Pero, en enero del año siguiente se sublevaron los mudéjares de las sierra de Ronda y Marbella, quienes obtuvieron una importante victoria sobre las tropas 
cristianas -marzo de 1501-. A estas alturas se habían hecho "patentes todos los sentimientos de frustración que existían en el colectivo musulmán y todo el recelo que despertaban entre los cristianos ${ }^{47}$. Fue entonces cuando definitivamente los Reyes, aparte de intensificar la acción militar para terminar con la rebelión, decidieron que ya no quedaba otra opción que la planteada años antes a los judíos: o los mudéjares castellanos, rebeldes o no, aceptaban el bautismo, o se verían obligados a salir de los dominios territoriales de la Monarquía, lo que concretaron en decreto de 11 de febrero de 1502. Forzados por las circunstancias, la inmensa mayoría se inclinó por la conversión; siguiendo los argumentos del teólogo magrebí Ahmed ben Yunaa, aceptaron el fingimiento -práctica de la taqiyya-para poder permanecer en su tierra bajo el poder político cristiano $^{48}$. Era la constatación oficial del fin del proyecto de una sociedad dual; a partir de ese momento se planteó desde el poder un verdadero programa para erradicar definitivamente el Islam de las tierras granadinas ${ }^{49}$. A juicio de Suberbiola, la conversión general, acto con una clara finalidad política, era necesaria, «ya que la religión musulmana actuaba, igualmente que la cristiana, como instancia ideológica dominante del islam» 50 .

A cambio de convertirse, con lo que pasaron a depender del régimen fiscal castellano ${ }^{51}$, que sustituyó al nazarí, los cristianos nuevos se vieron libres del castigo por haberse sublevado, pudiendo de momento conservar los baños públicos, sus vestimentas tradicionales y el uso de la lengua árabe. Por parte cristiana, se sabía la falsedad de la conversión, pero se pensaba que era el primer paso para que dicha conversión pasase a ser verdadera en un futuro más o menos próximo. Oficialmente, en 1502, legalmente se había conseguido la unidad religiosa en la Corona de Castilla; sin embargo, la realidad era bien distinta, ni la unidad de fe era un hecho auténtico, ni había comenzado una verdadera castellanización de los mudéjares. La inmediata aparición del problema morisco es un evidente mentís de que, en la práctica, se hubiese conseguido triunfo alguno en el camino de la integración. No obstante, las autoridades iban a proceder como si todos los musulmanes irrecuperables hubiesen optado por el destierro, mientras que permanecían los que deseaban asimilarse, algo que desde la óptica del poder se iba a perseguir de inmediato con ahínco, "porque era una exigencia política y porque mantener la segregación hubiera sido confesar que la cristiandad de los moriscos reposaba en una falsedad ${ }^{52}$. En cuanto a los moriscos, iban a mostrar una actitud poca propicia para caminar por las vías asimiladoras emanadas del gobierno, ya que, en realidad, ellos sencillamente «habían creído que sólo 
con aceptar el bautismo se les dejaría en paz» ${ }^{53}$. El profesor Ladero ha sintetizado la situación del modo siguiente:

Los granadinos aceptaron el bautismo con fingimiento y repudio interior, y la práctica secreta del Islam, la conservación de sus preceptos, si bien algo degenerada por la ignorancia y el aislamiento, persistieron en los decenios siguientes a tenor de una práctica generalmente aceptada, la de la «taqiyya»o disimulación. Los moriscos se aferraban a su religión como parte del legado cultural de sus antecesores; el rechazo del cristianismo estaba íntimamente unido a la pertenencia de éste a otro círculo cultural distinto del suyo, que les había sido impuesto y que convivía con ellos por la fuerza de las ramas vencedoras ${ }^{54}$.

En la ciudad de Granada la situación se había normalizado en fecha temprana. Desde el momento en que concluyeron los bautismos masivos ya no había motivo para mantener la dualidad administrativa hasta entonces vigente en el reino. El propio régimen municipal granadino se fue completando a lo largo de 1500 hasta que se asemejó al de otras grandes ciudades del territorio. Se formó así un ayuntamiento integrado por 24 caballeros regidores designados por los monarcas, dos alcaldes ordinarios, un alguacil mayor, 20 jurados y otros tantos escribanos del número, aparte de uno para el cabildo; un concejo, por lo demás, que extendía su jurisdicción hasta buena parte de la Vega, la Alpujarra y la costa -Real Decreto de 23 de septiembre de 1500 -

\section{El programa de castellanización}

Con el objeto de conseguir una definitiva asimilación, las autoridades civiles y religiosas proyectaron una nueva política de evangelización -Real Cédula de 24 de octubre de 1500-, cuya primera finalidad era romper la cohesión social existente entre los miembros de la comunidad morisca, por ello, en la política a seguir se prestaba una especial atención a la catequesis de las mujeres y de los niños. Se inició, de este modo, un programa político en el que castellanizar y cristianizar tomaban en la práctica un mismo significado, según el cual conseguir que los vencidos se convirtiesen en súbditos leales pasaba por su castellanización y, por tanto, por su aceptación de la fe cristiana.

Relativamente pronto, hacia 1510 , se percibió que, pese a los deseos regios, la actuación evangelizadora, realizada con medios inadecuados y sin excesivo entusiasmo, resultaba, al menos, insuficiente para lograr los fines propuestos, en especial debido a la fuerte resistencia de los moriscos a la misma; también parecía quedar claro que la persistencia de de- 
terminadas prácticas culturales ayudaban de forma inequívoca a mantenerse fieles a la práctica de su religión. Todo ello determinó que se pasase a tomar otras medidas de control y de represión en las que ya no sólo se contemplaba el hecho religioso, sino que las mismas alcanzaban un campo cultural más amplio. Se trataba de un verdadero plan de aculturación cuyo último objetivo era destruir las señas de identidad de los vencidos; así pues, entre 1511 y 1513, se promulgan una serie de cédulas en este sentido -regulación de las zambras, ritual de sacrificio de los animales, uso de armas blancas, limitaciones de vestimenta, prohibición de ejercer algunas profesiones...-. Se intentaba destruir las peculiaridades de la cultura morisca, ya que la continuidad de las mismas hacía imposible la integración pretendida. De hecho, esta nueva actitud suponía el abandono de la creencia en una fácil asimilación y añadía la consideración de los moriscos como un sector marginado de la población. De ahí que se abandonara la igualdad fiscal y que fuesen sometidos al sistema de fardas, impuestos de los que, salvo alguna excepción, estaban exentos los cristianos viejos.

Ahora bien, este proceso iba más allá de modificar la situación religiosa y cultural, por importante que ésta fuese; se trataba de poner en marcha un proyecto de castellanizar en todos los aspectos posibles la vida de los granadinos, intentando, incluso, cambiar la propia fisonomía urbana. Las autoridades cristianas de Granada iban a intensificar, por tanto, la transformación urbanística de la ciudad que había comenzado en realidad al mismo tiempo que la conquista.

La capital granadina, aunque atrayente y admirada por sus bellezas, parecía extraña e inquietante a todos los que llegaban del norte y, por ello, no se iban ahorrar esfuerzos para tratar de cambiarla hasta en los menores detalles. Se buscaba la extirpación del Islam del ambiente urbano granadino, pero esta era una empresa que requería tiempo. Así, a pesar de que en 1501 se planteó un programa, vasto y ambicioso, casi nada fue construido hasta el advenimiento de Carlos V, continuándose, en menor medida, en el reinado de Felipe II: ensanchamiento de calles, nuevo alineamiento de las mismas, apertura de plazas, nuevas construcciones arquitectónicas,... Incansablemente los trabajos se continuaban. Granada fue, por ello, una ciudad «en obras» en el siglo XVI. En el siglo XVII se contentaron con terminar el gran proyecto aportándole complementos de detalle.

Sin embargo, este esquema no es aplicable a toda la ciudad; es válido para la ciudad baja y, en parte, para las colinas de la Alhambra y del 
Mauror, pero no, para el Albaicín. Los coetáneos subrayaron, justamente, que siguió siendo una ciudad en la ciudad. La edificación de las iglesias y conventos no alteró sus rasgos fundamentales; habiendo permanecido como lugar de residencia de los moriscos, el Albaicín conservó sus caracteres muy acusados de ciudad musulmana. Era la plasmación urbanística de la difícil coexistencia de dos comunidades que vivían de espaldas una a la otra.

\section{Colofón}

Teniendo en cuenta lo expuesto en las páginas anteriores parece que la respuesta a la pregunta planteada al comienzo sobre si fue posible establecer unas líneas de convivencia entre musulmanes y cristianos en la Corona de Castilla durante el reinado de los Reyes Católicos es netamente negativa, sin duda por las inconciliables posturas mantenidas tanto por los mudéjares/moriscos como por los cristianos viejos. Ahora bien, esta imposible convivencia hay que entenderla con referencia a la mayoría de la población morisca, a la que se puede calificar como «un grupo social cerrado, casi impermeable a influencias extrañas ${ }^{55}$, cuya resistencia se expresó de múltiples formas: «rebeliones, manifestaciones violentas de oposición puntual a las autoridades, operaciones organizadas por los monfíes (considerados por los musulmanes como defensores de la fe y por los cristianos como bandidos) y maniobras de los corsarios magrebíes» ${ }^{56}$; pero no así con respecto a las élites que no se habían exiliado - una minoría fácilmente integrada- y a otros grupos de distintos niveles -y de los que en general aún nos queda mucho por conocer-, cuyos integrantes no sólo se asimilaron, sino que, además, trataron por todos los medios de ocultar sus orígenes y perderse en el anonimato para lograr una plena integración, evitando así posibles discriminaciones. De ahí que con pleno acierto se haya podido escribir que «frente a la aculturación impuesta por el poder castellano existieron numerosos casos de asimilación activa y voluntaria» ${ }^{57}$, -prueba de que muy posiblemente el número de asimilados en otras circunstancias podía haber sido bastante mayor-. Éstos moriscos integrados, difícilmente cuantificables, sí que consiguieron una plena convivencia, pero la misma tuvo como precio la renuncia a sus raíces religiosas y culturales, hecho que dentro del contexto histórico puede considerarse dentro de la normalidad en la Europa de la época, donde la disidencia religiosa era contemplada como un ejemplo de auténtica subversión social. 


\section{Musulmanes y cristianos: La imposibilidad...}

\section{Notas}

1 Cardaillac, Louis, «1492, rupture ou continuité?», en Tourments, doutes et ruptures dans l'Europe des XVIe XVIIe siècles. Actes du Colloque organisé par l'Université de Nancy II, 25-27 novembre 1993. París, Honoré Champion Editeur, 1995, pp. 9-10.

2 Ladero Quesada, Miguel Ángel, «Isabel y los musulmanes de Castilla y Granada», en J. Valdeón Baruque (ed.), Isabel la Católica y la política. Valladolid, Ámbito, 2001, p. 95.

3 El mismo Cardaillac ha escrito al respecto: «Ce n'est pas là un phénomène proprement espagnol, méme s'il est, comote tenu des circonstances, particulièrment accentué en Espagne. LÉurope de la Renaissance voit l'irruption des nationalités. Le concepte racialreligieux se comprend comme national, et deviene donc un concepte réducteur nacionalcatholique, Le concepte d'etranger supposer la disqualification des no-chrétiens». Cardaillac, L., «1492, rupture ou..., p. 10.

${ }^{4} \mathrm{El}$ problema judío - del cual aquí no nos ocupamos-, aunque con connotaciones similares de rechazo, presenta asimismo unas características bien diferentes y de honda raigambre en toda Europa.

5 Galán Sánchez, Ángel, «Los moriscos de Málaga en la época de los Reyes Católicos», Jábega, 39 (1982), p. 56. 29-30.

${ }^{6}$ Maíllo Salgado, Felipe, De la desaparición de al-Andalus. Madrid, Abada, 2004, pp.

7 Cortés Peña, Antonio Luis, «A propósito de la Iglesia y de la conquista de Granada», en el vol. misceláneo Iglesia y cultura en la Andalucía moderna. Tendencias de la investigación, estado de las cuestiones. Granada, Proyecto Sur, 1995, p. 136.

${ }_{8}$ García Martín, Pedro, La péñola y el acero. La idea de Cruzada en la España del Siglo de Oro. Sevilla, S. \& C., 2004.

9 Ladero Quesada, M.A., «Isabel y los musulmanes..., p. 102.

${ }^{10}$ López de Coca Castañer, José Enrique, «El período nazarí (siglos XIII-XV)», en J.E. López de Coca Castañer y R.G. Peinado Santaella, Historia de Granada. II. La época medieval. Siglos VIII-XV. Granada, Don Quijote, 1987, p. 351.

11 Ladero Quesada, M.A., «Isabel y los musulmanes..., p. 104.

12 Una tipología de las mismas generalmente aceptadas puede verse en Ladero Quesada, Miguel Ángel, Castilla y la conquista del Reino de Granada. Granada, Diputación Provincial, 1987, pp. 78-97.

13 Hubo en realidad unas postreras capitulaciones, redactadas en la misma línea que las de la capital, las que supusieron la rendición de la cercana localidad de Alfacar. Ladero Quesada, Miguel Ángel, Granada después de la conquista. Repobladores y mudéjares. Granada, Diputación Provincial, 1988, pp. 382-383.

14 Garrido Atienza, Manuel, Las capitulaciones para la entrega de Granada. Edición facsímil del original de 1910. Estudio preliminar de J.E. López de Coca Castañer. Granada, Universidad, 1992.

15 Los Reyes no dudaron en estimular la emigración, siempre que el hecho no supusiese un despoblamiento excesivo, como medida de desembarazarse así de los elementos que podían ser más peligrosos para su política de integración. En otro lugar he expresado «que 1492 -con el decreto de expulsión de los judíos de los territorios de la Monarquía española- y 1502 -con el de los mudéjares- se insertan dentro del conjunto de expulsiones que marcan el preámbulo de las emigraciones forzadas por motivos religiosos que iban a proliferar en el mundo europeo de la época moderna. En todos los casos se trata- 
ba de encontrar la cohesión social, buscando la homogeneización de la sociedad a través de una misma fe religiosa; no es un fenómeno exclusivamente español, aunque en la España del momento alcanza cotas debido a las circunstancias particulares en las que se crea la Monarquía de los Reyes Católicos». Cortés Peña, Antonio Luis, «La emigración de los musulmanes granadinos (1482-1502), primer acto de una trágica ruptura", ponencia presentada en el Seminario La mobilité des personnes en Méditerranée de l'Antiquité à l'époque moderne. Madrid, Casa de Velázquez, 30-31 de enero de 2004, [en prensa].

${ }^{16}$ López de Coca Castañer, José Enrique, «Las capitulaciones y la Granada mudéjar», en M.A. Ladero Quesada (ed.), La incorporación de Granada a la Corona de Castilla. Actas del symposium conmemorativo del Quinto Centenario. Granada, Diputación Provincial, 1993, p. 263.

17 Galán Sánchez, Ángel, Los mudéjares del reino de Granada. Granada, Universidad/ Diputación Provincial, 1991, p. 59.

18 Suárez Fernández, Luis, Los Reyes Católicos. La expansión de la fe. Madrid, Rialp, 1989, p. 136.

19 Galán Sánchez, Ángel, «Notas para el estudio del origen de la «cuestión morisca». Las bases socioeconómicas: El Obispado de Málaga (1500-1515)», Historia. Instituciones. Documentos, 9 (1982), p. 311.

20 «Así no es de extrañar que estas autoridades locales sean el blanco de futuras represalias: no pocos perecerán en la revuelta de 1501 y, los más, verán arrasadas sus casas y haciendas». Acién Almansa, M. y López de Coca Castañer, J.E., «La cuestión mudéjar en tierras de Málaga», Jábega, 12 (1975), p. 42

${ }^{21}$ Redondo, Augustin, «El primer plan sistemático de asimilación de los moriscos granadinos: El del doctor Carvajal (1526)», en el vol. colectivo Les Morisques et leur temps. París, CNRS, 1983, p. 113.

${ }^{22}$ Francisco Márquez Villanueva ha escrito al respecto que «la política que se aplicó a los moriscos no fue asimiladora, sino de persecución religiosa y genocidio cultural» («El problema historiográfico de los moriscos», en su vol. colectivo El problema morisco (desde otras laderas). Madrid, Libertarias, 1991, p. 130). Es cierto, pero habría que preguntarse si era posible en aquel contexto histórico otre tipo de asimilación. Mi respuesta es desde luego negativa, aunque bien es verdad que quizás podían haberse utilizado otros métodos, pero, repito, en aquel contexto histórico, quiero creer que no con nuestros parámetros actuales, asimilación e integración llevaban consigo la aculturación y el consiguiente rechazo de la «otra religión».

${ }^{23}$ Grima Cervantes, Juan Antonio, «Las capitulaciones pactadas en 1488 y en 1501 entre los Reyes Católicos y los mudéjares de Vélez Blanco y Vélez Rubio», Revista Velezana, 6 (1987), pp. 76 y 77.

24 Maíllo Salgado, F., De la desaparición de..., p. 32.

25 Suberbiola Martínez, Jesús, «La erección parroquial granatense de 1501 y el reformismo cisneriano", Cuadernos de Estudios Medievales, XIV-XV (1985-1986), p. 117.

26 Szmolka Clares, José, «Los comienzos de la castellanización del reino de Granada", en Actas del I Congreso de Historia de Andalucía. Andalucía medieval. Córdoba, Monte de Piedad y Caja de Ahorros, 1978, II, p. 412.

27 Ladero Quesada, M.A., Granada después de la..., p. 4.

28 Suberbiola Martínez, Jesús, «La ordenación parroquial malacitana de 1505 y su reformación", Baetica, 8 (1985), p. 312.

29 Peinado Santaella, Rafael Gerardo, «El reino de Granada en tiempos de los Reyes Católicos», Revista de la Asociación Europea de Profesores de Español, 40/41 (1992), p. 19. 


\section{Musulmanes y cristianos: La imposibilidad...}

30 López de Coca Castañer, José Enrique, «El repartimiento de Vélez-Málaga», en su obra miscelánea El Reino de Granada en la época de los Reyes Católicos: Repoblación, comercio y frontera. Granada, Universidad, 1989, I, p. 60.

31 Galán Sánchez, A., Los mudéjares del reino..., p. 319.

32 Castillo Fernández, Javier, «El origen del Consejo y la formación de la oligarquía ciudadana en Baza (1492-1520)», Chronica Nova, 20 (1992), p. 40.

33 Acién Almansa, M. y López de Coca Castañer, J.E., «La cuestión mudéjar en..., p. 36.

${ }^{34}$ López de Coca Castañer, José Enrique, «El reino de Granada como frontera: Organización de su defensa durante el reinado de los Reyes Católicos (1492-1516)», en La organización militar en los siglos XV y XVI. Actas de las II Jornadas Nacionales de Historia Militar. Málaga, 1993, p. 94.

35 Barrios Aguilera, Manuel, La Granada morisca, la convivencia negada. Granada, Comares, 2002.

36 Galán Sánchez, Ángel, «Algunos rasgos de la propiedad mudéjar en la Ajarquía de Vélez-Málaga», Baetica, 11 (1988), p. 363. Véase asimismo, Suberbiola Martínez, Jesús, «Fisco, franquicias y problemas en la repoblación de Málaga (siglos XV-XVI)», Cuadernos de Estudios Medievales, II-III (1974-1975), p. 167.

37 Acién Almansa, Manuel, «Dos textos mudéjares de la serranía de Ronda (1491)», Cuadernos de Estudios Medievales, II-III (1974-1975), p. 253.

38 Cortés Peña, Antonio Luis, «Mudéjares y moriscos granadinos, una visión dialéctica tolerancia-intolerancia», en M. Barrios Aguilera y B. Vincent (eds.), Granada 14921992. Del Reino de Granada al futuro del Mundo Mediterráneo. Granada, Universidad/Diputación Provincial, 1995, p. 105.

39 Garrido Aranda, Antonio, Organización de la Iglesia en el Reino de Granada y su proyección en Indias. Sevilla, Escuela de Estudios Hispanoamericanos, 1980.

40 Suberbiola Martínez, J., «La erección parroquial granatense..., p. 116.

41 Szmolka Clares, José, El Conde de Tendilla, primer Capitán General de Granada. Granada, Ayuntamiento, 1985, p. 80.

42 Hay quien ha defendido que el nuevo clima de dureza con el vencido en realidad había triunfado a partir de 1497, año en el que fueron defenestrados del equipo de gobierno de los Reyes Católicos el grupo de políticos de origen judeoconverso opuesto a la intransigencia de los sectores más conservadores. Suberbiola Martínez, Jesús, Real Patronato de Granada. El arzobispo Talavera, la Iglesia y el Estado Moderno. Granada, Caja General de Ahorros, 1985.

43 Acontecimiento verdaderamente intolerante y lamentable desde diversos puntos de vista, pero que se ha convertido en arma arrojadiza, utilizando cifras desmesuradas, para aquellos que han convertido a la manipulación y a la mistificación en protagonistas de la explicación «histórica» de la conquista de Granada.

44 Szmolka Clares, José, El Conde de Tendilla..., pp. 81-82.

45 Monroe, James T., "A curious morisco appeal to the ottoman empire», Al-Andalus, XXXI (1966), p. 285.

46 Szmolka Clares, José, «Los inicios de una imposible convivencia: la Granada mudéjar (1492-1502)», en A. Temimi (ed.), Mélanges Louis Cardaillac. Zaghouan, Ftersi, 1995, II, p. 671.

47 Argente del Castillo Ocaña, Carmen, «Últimos episodios de cautiverio fronterizo en la revuelta mudéjar, 1500-1501», Roel, 9/10 (1988/1989), p. 113.

48 Cardaillac, Louis, Moriscos y cristianos. Un enfrentamiento polémico (1492-1640). Madrid, Fondo de Cultura Económica, 1979, pp. 85-86. 


\section{Antonio Luis Cortés Peña}

49 Cortés Peña, A.L. y Vincent, B., Historia de Granada. III. La época moderna. Siglos XVI, XVII y XVIII. Granada, Don Quijote, 1986, pp. 24 y ss.

50 Suberbiola Martínez, Jesús, «Política fiscal en la conversión general mudéjar», $B a$ etica, 2 (1979), p. 251.

51 En teoría se trataba de una igualación fiscal, algo, no obstante, falso en la realidad, ya que «los repobladores gozan de una amplia gama de exenciones tributarias -prorrogadas varias veces ante el fracaso de la repoblación- de la que quedan fuera los nuevos vasallos cristianos». Galán Sánchez, A., «Los moriscos de Málaga..., p. 11. Véase también López de Coca Castañer, José Enrique, «Privilegios fiscales y repoblación en el reino de Granada», Baetica, 1 (1978), pp. 205-223.

${ }^{52}$ Domínguez Ortiz, Antonio, «Notas para una sociología de los moriscos españoles», Miscelánea de Estudios Árabes y Hebraicos, XI (1962), p. 44.

53 Cardaillac, Louis, «El enfrentamiento entre moriscos y cristianos», Chronica Nova, 20 (1992), p. 29.

${ }^{54}$ Ladero Quesada, Miguel Ángel, Granada. Historia de un país islámico (12321571). Madrid, Gredos, 1969, p. 164.

55 Domínguez Ortiz, A., «Notas para una sociología..., p. 44.

56 Vincent, Bernard, «El río morisco», en el vol. colectivo La expulsión de los moriscos. Madrid, Bancaja, 1998, p. 126. En el artículo se hacen interesantes precisiones a la teoría de Márquez Villanueva sobre los tres graves errores de la historiografía sobre los moriscos.

57 Castillo Fernández, Javier, «La asimilación de los moriscos granadinos: un modelo de análisis», en A. Mestre Sanchís y E. Giménez López (eds.), Disidencias y exilios en la España Moderna. Alicante, Universidad/A.E.H.M., 1997, p. 349. 